\title{
Principles for discharging patients from acute care: a scoping review of policy
}

DOI:

10.12968/bjon.2016.25.20.1135

\section{Document Version}

Accepted author manuscript

Link to publication record in Manchester Research Explorer

\section{Citation for published version (APA):}

Lees-Deutsch, L., Yorke, J., \& Caress, A-L. (2016). Principles for discharging patients from acute care: a scoping review of policy. British journal of nursing (Mark Allen Publishing). https://doi.org/10.12968/bjon.2016.25.20.1135

\section{Published in:}

British journal of nursing (Mark Allen Publishing)

\section{Citing this paper}

Please note that where the full-text provided on Manchester Research Explorer is the Author Accepted Manuscript or Proof version this may differ from the final Published version. If citing, it is advised that you check and use the publisher's definitive version.

\section{General rights}

Copyright and moral rights for the publications made accessible in the Research Explorer are retained by the authors and/or other copyright owners and it is a condition of accessing publications that users recognise and abide by the legal requirements associated with these rights.

\section{Takedown policy}

If you believe that this document breaches copyright please refer to the University of Manchester's Takedown Procedures [http://man.ac.uk/04Y6Bo] or contact uml.scholarlycommunications@manchester.ac.uk providing relevant details, so we can investigate your claim.

\section{OPEN ACCESS}


Principles for discharging patients from acute care: a scoping review of policy

Liz Lees-Deutsch ${ }^{1,2}$, Janelle Yorke ${ }^{2,3}$ and Ann-Louise Caress ${ }^{2,4}$

1) Medicine, Heart of England NHS Foundation Trust, Birmingham

2) School of Nursing, Midwifery and Social Work, University of Manchester and University

3) The Christie NHS Foundation Trust

4) Hospital of South Manchester NHS Foundation Trust

Accepted for publication: October 2016

\section{INTRODUCTION}

In the United Kingdom (UK), patient discharge from hospital remains a topical issue having received intense media reporting during 2016 drawing the public attention to an unfolding crisis (Divya, in International Business Times, 2016). High patient volumes, poor patient flow through Accident and Emergency Departments $(A \& E)$ created chaos and inability to meet longstanding fourhour treatment targets (NHS Plan, Department of Health, 2000). To positively influence the crisis in A\&E's is dependent on other areas of the hospital efficiently discharging patients to maintain patient flow (Royal College of Physicians (RCP), Toolkit 2, 2011). Acute Medicine Units (AMUs) are a significant part of the services that treat large volumes of patients, who present to hospital as an emergency (RCP), 2007, 2011) and are a growing area of practice reported globally (Jenkins, Barton et al, 2010). In both A\&E's and AMUs staff report feeling pressured to 'move or discharge patients earlier than desired' (Hoyle and Grant, 2015). Despite the reforms in emergency healthcare delivery, there remain critical issues with discharging patients from hospital (National Audit Office, 2016, House of Commons Committee of Public Accounts, 2016). 'Poor communication, information sharing and shared decision making', are just a few of the problems highlighted at the point of patient admission to hospital (Parliamentary and Health Service Ombudsman, 2016).

The longstanding principle that continues to proliferate the literature states that discharge planning should 'begin on admission' to hospital and be reviewed throughout the inpatient stay (Atwal, 2002). Nevertheless, the 
process of admission to hospital has changed beyond all recognition in the last ten years (NHS England, 2014, NHS England, 2015, Atwal et al, 2012) such that admitting acutely ill medical patients to hospital is no longer conducted on most in-patient wards; having become the domain of AMUs (RCP, 2007). The length of patient stay in hospital are getting shorter and services previously reliant upon beds are now delivering care in ambulatory, intermediate or outpatient settings (RCP, 2014). Such changes separate the process of patient assessment/admission from in-patient wards adding in a new, albeit brief 'assessment' stage in the patient's care pathway. Frequent patient transfers from AMUs to other areas, have the potential to fragment the transfer of information from the admission and discharge process (Groene et al, 2012). Thus potentially creating some of the problems reported in the press that require improvement (Diva, 2016).

Currently new policy guidance (National Institute for Health and Care Excellence NICE, NG: 27, 2015) focuses on predominantly on improving the transfer of older people to other care settings (e.g., to intermediate care facilities), while guidance for discharging patients (directly home) from acute settings such as AMUs is not developing so explicitly. Moreover, with our ageing population, patient complexity; policies are increasing and the guidance for this is extensive (British Geriatrics Society: The Silver Book, 2012, Edmans et al, 2013, RCP, Toolkit 3, 2012, Department of Health (DH), 2007, 2011, 2013, Age Concern, 2015). This creates the myriad of patient discharge policies developed for in-patient and rehabilitation wards, $(\mathrm{DH}$, 2003, DH, 2004, DH, 2010). Deciphering what are the most appropriate actions to ensure safe patient discharge from AMUs is consequently very challenging due the enormous difference in setting, predominantly created by the short proximity in time between admission and discharge (RCP, 2007, RCP Toolkit 3, 2012). Ultimately there remains a gap in guidance to support the large volumes of patients attending AMUs to ensure patient discharge is safely expedited.

This article presents a Scoping Review of patient discharge policy and guidance across the UK from 2002 to 2016 which has been examined, 
analysed and interpreted through Arksey and O'Malley's, systematic approach (2005). This scoping review is specifically concerned with developing appropriate guidance to support the safe discharge of patients from AMUs.

Note: Patient discharge is the term used throughout to indicate discharge out of hospital to end point destination. The term 'Transfer' is used throughout in relation to the policies and guidance where patients are transferred to another care setting, prior to their end point destination, e.g. for intermediate care. Both types of patient would however be discharged or transferred in accordance with a discharge Policy. Whereas internally transferred patients going to another ward in the hospital are transferred in accordance with a Transfer Policy.

\section{Acute Medicine Units and discharge planning}

AMUs in the UK specialise in the initial assessment, diagnosis, stabilization and subsequent discharge or transfer of patients (RCP, 2007). They facilitate an enormous throughput of patients. While AMUs adhere to treatment national quality targets (Society for Acute Medicine, 2012), the four-hour target (NHS Plan, 2000) is not relevant as most AMUs accommodate patients for up to 72 hours (RCP, Toolkit 2, 2011).

\section{AIM}

To identify relevant national discharge policies and guidance to critically consider them with particular reference to developing bespoke principles to guide clinical practitioners in the delivery of safe, effective patient discharge from AMUs.

\section{METHODS}

\section{Scoping Review}

Arksey and O'Malley's (2005) five-stage framework widely used in policy reviews has been used (Levac, Colquhoun et al, 2010). Each stage was conducted using relevant retrieval methods to ensure objectivity within the framework (Daudt, Mossel et al, 2013). 
Scoping studies have been defined as having several functions; they with contextualize a breadth of knowledge on a given topic and map the key concepts/resources to establish gaps and overlaps in policy or practice maybe (Anderson et al, 2008, Levac and Colquhoun et al, 2010).

The stages of the framework and retrieval methods used within each stage are detailed here:

1. Identifying the review questions: four broad questions were formed to frame the review based on the target population, intervention, comparison and outcome (PICO) approach (Fineout-Overholt \& Johnston 2005) as recommended in a critique of Arksey and O'Malley's methodology (Anderson, 2008).

2. Identifying relevant studies: potentially relevant policies to include in the review were identified using an inclusion and exclusion criteria (Evidence for Policy Practice Information, EPPi, 2010) to encompass the topic, population, setting, discharge process and standards.

3. Study selection: the ECLIPSE framework was used (Wildridge and Bell, 2004) to enable the systematic recording and scrutiny of the detail within policies $(n=28)$.

4. Charting the data: Commonalities and differences in the 28 policies were identified and mapped using a matrix approach to identify overlaps and gaps across the policies. The ten discharge process steps/principles from within the English Policy (DH, 2010) were used as the 'indicators' as they principles use commonly within acute policy in the NHS.

5. Collating, summarizing and reporting the results: this was conducted using a Policy Analysis Template (online resource, combat poverty, 2006) to provide a consistent organization to identify and extract policy characteristics. Whilst the aim was not to provide weighting or impact of the policy, it did provide clarity regarding findings and issues arising. 
An additional optional framework stage (6) of 'Consultation' was not adopted, however a multi-disciplinary practice based task and finish group of clinical staff was convened at the outset of the review process, Stage 0 (Levac et al, 2010).

\section{Stage 0 - The task and finish group}

The task and finish group comprised six staff from with expertise in patient discharge namely, capacity manager, nurse manager, discharge coordinator, physiotherapist, Consultant Geriatrician and Social Worker employed in acute care within an NHS Hospital Trust in the UK. The group's function and remit is listed below,

(1) Decide the scope of policy to be included in the review

(2) Agree the use of the ten core principles for charting (DH, 2010)

(3) Devise the inclusion and exclusion criteria and search terms

(4) The focus of the search and rationale

The challenges surrounding each area 1 to 4 are illuminated:

(1) The scope of potential policy spanned health and social care, which was narrowed by distinguishing between simple and complex discharges (Dyer and Temple, Chapter 6, p98: Lees, 2007). Complex discharges were regarded as outside the function of an AMU so the policy scope was narrowed to only include 'simple discharges' (DH, 2004a).

(2) Members of the group stated that ten principles within the English Policy (DH, 2010) were largely ignored quoting 'they don't represent operational reality in an AMU'. For example, the group instead described specific behaviours 'that make patient discharge work' in AMU. This provided real life perspectives on 'what really happens in practice' enhancing the overall contextual focus and purpose of the Scoping review. Nevertheless, as the ten principles ( $\mathrm{DH}, 2010)$ are adopted widely in hospital policies, they were deemed suitable for use as a baseline with the 'Charting' stage of the Scoping review process. 
(3) The group expressed concerns that the integration of specialist policies (e.g., mental health and safeguarding) 'must not elongate' the discharge process from AMU's. Some specialist patient groups (e.g., homeless) however, were included to incorporate aspects related to patient safety and represent the diversity of patients seen in an AMU.

(4) Financial assessment and comprehensive assessment of older patients on admission to AMU evoked most disagreement amongst group members. The majority of members however, unequivocally contested both aspects, as issues that could 'wait' until the patient was transferred out of AMU. This aspect indicates that some patient discharge guidance, given the context of an AMU is inappropriate for the setting.

\section{Stage 1 - policy review questions}

The following four questions were developed to guide the policy review process aided by the PICO development framework namely, Population, Intervention, Control and Outcome (Fineout-Overholt \& Johnston 2005) described within table 1.

Insert Table 1 here

1. What if any, national discharge planning policy exists across the UK to guide the discharge of patients from acute areas/acute medicine units?

2. What are the fundamental components, similarities and differences identified throughout the UK discharge policies?

3. What if any, are the key recommendations regarding the risk assessment of patients to be discharged from acute care?

4. What if any, commonalities from the scoping review could be integrated to revise the principles of discharge practice for AMUs? 


\section{Stage 2 - identify relevant studies}

\section{Search rationale}

Included policies were, acute care, safeguarding, homeless and dementia patients. Excluded policies were, mental health ${ }^{1}$, commissioning, complex discharge and social care.

\section{Search strategy}

2002 was selected as the starting point for this scoping review following the plethora of policy generated for discharge at this time.

The search term "Patient Discharge" was identified as the only term within the Medical Subject Heading Index (MeSH, 2016) and is defined as;

"The administrative process of discharging the patient, live or dead from hospitals or other health facilities"

This MESH term was used throughout the review to retain clarity regarding the interpretation of 'discharge' - namely, 'patients who are discharged from and subsequently leave hospital' (Davis et al, 2005). This is emphasized because new terms are being promulgated by policy makers globally such as, 'transfer of care', which can give rise to misunderstanding especially in an AMU where 'patient transfers' to in-patients wards and other settings (intermediate) are another different - yet integral part of its workload (Lees, 2012, Lees, 2013, DH, 2014).

\section{Web search and search terms}

The Evidence Services Health Information Resources within the Health Management Information Consortia (HMIC) and specialist society websites were searched. Seven searches were conducted with different combinations of the terms as listed:

- Patient discharge and adults

- Patient discharge and acute hospital

\footnotetext{
1 staff in AMU need a 'knowledge of' in-reach/liaison teams to instigate a specialist review, rather than 'specialist knowledge
} 
- Patient discharge and discharge process

- Patient discharge and acute care

- Patient discharge and emergency care, not elective

- Patient discharge and homeless

- Patient discharge and dementia

Inclusion and exclusion criteria for key terms were developed using guidance from the Evidence for Policy and Practice Information - coordinating centre (EPPi, 2010), which encompasses (1) topic, (2) population and (3) setting (Table, 2).

Insert table 2 here

\section{Stage three - policy selection}

The ECLIPSe ${ }^{2}$ framework (Wildridge and Bell, 2004) was used to systematically identify and extract the most pertinent aspects within the policy (Table, 3). In addition, to ensure the interpretation of simple discharge was consistent across the policies reviewed, a definition for simple and complex patient discharge was applied (Dyer and Temple, in Lees 2007).

Table 3 insert here

\section{Stage four - charting the data}

Following agreement from the task and finish group (stage 0) the English policy principles (Ready to Go?, DH, 2010) were used as the baseline for the comparison and contrasting of commonalities across the UK policies. The rationale being that the discharge principles from each of the four UK discharge policies are a common theme (NHS Wales, 2013, Scottish Health Executive, 2009, Health Services Executive, 2014); these were charted in Excel (Mac) using a matrix approach (Table 4).

\footnotetext{
${ }^{2}$ ECLIPSe is an established framework to guide policy review - expectation, client group, location, impact, professional, service and evaluation.
} 
While stages $4 \& 5$ are reported separately (as per Scoping Framework) the summary of the data to be 'charted' actually occurred iteratively and simultaneously on the policy reporting templates (stage 5). This involved moving between the stages $4 \& 5$ to fully inform the charting process. Hence, this enabled interpretation of the similarities across the 28 policies, using the topic expertise of the lead author. For example; estimating dates for discharge is a core principle within the English Policy (DH, 2010), but this is also called 'predicting dates for discharge' (NHS Wales 2013, NLAlH, 2007), Estimating lengths of stay (Health Services Executive, 2008), 'anticipated discharge date' (Scottish Health Executive, 2009); all of which can be interpreted as the day/date in which the patient is estimated to be able to go home. Once similarities were identified, these were underlined and noted in order to reduce overlaps across the core principles. This process was repeated iteratively for each of the principles identified within the UK Policies, which helped to identify new aspects policy and the summary of results (Table 4).

Insert table 4 here

\section{RESULTS}

\section{Stage five: collating, summarizing and reporting the results}

The process of summarising in-depth qualitative data from within each policy was carried out using nine key questions from a policy analysis template, (Combat Poverty, on line resource, 2006) to assist in understanding the policy contribution or contradictions. The diversity of policy, which included many examples of locality specific practice, service developments and strategic objectives (to mention a few) made the summary of data onerous.

\section{Nine key questions to summarize the policy}

1. Policy Title

2. What are the key facts?

3. What are they points made?

4. What are the key policies in the area?

5. Has the policy identified the key problem?

6. What is the discharge process? 
7. List the other organisations with interest in the topic

8. What is the key policy contribution?

9. What are the actions?

Review question 1: What if any national discharge planning policy exists across the UK to guide the discharge of patients from acute areas/acute medicine units?

This review established that a plethora of discharge policy exists, albeit its primary focus is outside the scope of an AMU. In summary, there were 248 policies/guidelines located and logged (from 2002 - 2016). Each abstract/executive summary from the 249 policies was appraised alongside the inclusion/exclusion criteria (Eppi, 2010). Only 78 policies were considered to fulfil most of the review inclusion requirements, these were retrieved in full and screened via the index and content listing. 34 of the 78 policies were removed at this stage when it was established they were intended for service development, commissioning or were locality specific policy. The remaining 44 policies were read in full, summarised and with the aid of the focus provided the ECLIPSe framework a further 17 were removed. The removed rationale for removing the 17 papers is detailed in table 5.

Insert table 5 here

Only 27 policies were retained at the time of the original search (see Prisma chart) plus 1, published during the course of the review bringing the total to 28, the process is illustrated on the PRISMA flow diagram (Moher et al, 2009).

Insert Prisma Diagram here

The 28 included Policies are listed in Table 6.

Insert table 6 here 
Review question 2: What are the fundamental components, similarities and differences identified throughout the UK discharge policies?

English discharge policy (DH, 2010) was used as a baseline to chart the principles/process steps across the core UK policies. Extrapolating, charting and interpreting the data revealed subtle and confusing differences in the terminology. For some components such as, 'carer involvement' it was ambiguous as to whether it was a separate step or intended to be included within several steps.

The approach taken by Scotland policy forms the greatest divergence from English, Irish and Welsh policy guidance; it comprises of a best practice template to be populated locally by service providers (SIGN 128, 2012). The similarities according to the frequency of reoccurring themes and differences were noted in Table 7.

Insert Table 7 here

Review question 3: What if any, are the key recommendations regarding the risk assessment of patients to be discharged from acute care?

Guidance provided for the risk assessment of patients across the four generic policies of the UK and other best practice guidance was confusing with little parity regarding what was meant by 'assessment'. Examples within the policies regarding patient assessment are namely, 'single assessment' ( $\mathrm{DH}$, National Service Framework, 2002), 'Unified assessment (NHS Wales, 2013)', 'Integrated assessment' (ECIST, 2013), 'shared assessment' (CSIP, 2007)', 'Comprehensive assessment' (The Silver Book, 2012) and 'common assessment' (DH, 2007).

The policies/guidelines indicate that some words have become out-dated, such as 'single' (DH, 2002), which is generally replaced with 'unified, integrated or shared', to indicate a holistic process of assessment takes 
places between service users (patients) and professionals (NICE, NG: 27, 2015, DH, 2014).

Recent policy guidance, however, does signpost specific considerations as principles for managing patient assessment in emergency care. Emergency care is comprised of A\&E, known as 'Emergency Department' with the usual services within. These principles were the most cognisant for patient discharge from AMU namely;

- Planning should begin as soon as possible

- Comprehensive Geriatric Assessment should be 'triggered'

- The appropriate timings of assessments

- Consider the types of teams who are best placed to assess

- The use of validated assessment tools to assess risk

- Consider the types of services needed out of hours to support discharge

- Care management after discharge.

Pages 18 \& 38, The Silver Book, 2012.

Relevant specialist guidance from the Alzheimer's Society, stated their discharge process must include:

- An assessment of the persons needs, living environment and support network

- Provision of a written care plan for the patient/carers on discharge

- Check to see if any services are required to re-instate on discharge

- Referral for assessment for possible continuing health needs

- The allocation of designated nurse, keyworker or social worker.

Page 2, 'Discharge Process', Alzheimer's Society, 2014.

Specialist guidance for homeless patients noted the key stages of a discharge pathway as: 
- Identification of homelessness status on admission

- Responding to a housing need - through appropriate contacts

- Ensuring a safe discharge with understanding of needs

Page 5, Key stages of a discharge pathway for homeless people, St Mungos, 2012.

In summary, the most wide-ranging best practice guidance regarding risk assessment was located, namely, The Silver Book (British Geriatrics Society, Intercollegiate Colleges, 2012). This book is an amalgamation of specialist assessments predominantly but not exclusively aimed at the needs of older people in emergency care; it contains six principles and twenty standards. Unlike other best practice guidance it advocates comprehensive risk assessment for discharge, suggesting a validated risk assessment for older people (Edmans, et al, 2011), namely Identification of Seniors at Risk (ISAR). Nonetheless, the problem with any risk assessment in a highly pressurised acute environment, such as AMU, is deciding what to include in the assessment, when and where is best to undertake this (Edmans, 2011, Edmans et al, 2013, Davis et al, 2005).

Review Question 4: What if any, commonalities from the scoping review could be integrated to revise the principles of discharge practice for AMUs?

The general commonalities throughout the policies are summarised below as;

- Timely patient assessment is essential - the corner stone to good practice

- Communication \& documentation - for every aspect of discharge practice

- Sharing and the transfer of information - 'transfer into / out of hospital'

- Patient \& carer involvement - on admission and for all changes/decisions

- Discharge coordination via discharge coordinators. 
These commonalities were used a structure to create six principles, each with relevant sub steps, which describe the pertinent tasks to safely expedite patient discharge from AMUs (Table, 8). This new approach provides more detail than the original Ten Policy Steps ( $\mathrm{DH}, 2010)$, it integrates the key points from the discharge \& transfer guidance (NICE, NG: 27, 2015) and major patient discharge concerns with recent UK reports (NAO, 2016, Public Accounts Committee, 2016).

The first draft of the discharge principles was circulated for patient and public feedback during 2016 to the membership of the Hospital's Clinical Research Ambassadors Group (CRAG). Comments received were considered in order to enhance the functionality of the principles and patient/carer interface, the points denoted in blue font are those added as a consequence of the consultation undertaken.

Bespoke discharge principles for AMUs: insert table 8 here

\section{DISCUSSION}

Over the last 13 years health policies have gradually started to integrate broader political and social issues within discharge planning policy, which reflects the increasing complexities of patient care/needs $(\mathrm{DH}, 2007$, The Silver Book, 2012, BMA, 2014, NICE NG: 27, 2015). There are many variances in phraseology in patient discharge policy, which makes policy incredibly onerous to interpret/decipher; especially in relation to an AMU environment when considering what is most appropriate for the diverse range of patients seen. Hence condensing and interpretation of the significant points from policy has proved to be an essential part of the scoping process.

There are similarities in the types of patients seen in both areas AMU and ED, however there is a huge difference in length of patient stay (4 hours to 72 hours), in this additional time AMUs start the discharge assessment process, which maybe continued if the patient is transferred internally to another ward, or speedily concluded if the patient is discharged. This is where principles (The Silver Book, 2012) for discharge are appropriate but required more 
information to guide busy practitioners.

The involvement of a task and finish group, was regarded by the lead author as a critical step, to complement the Arksey and O'Malley scoping framework (2005) to gain the understandings and interpretation of a wider multidisciplinary approach. The involvement of the patient and public ambassadors in reviewing the final principles enabled a pragmatic workable perspective into discharge principles for AMUs. They decided that 'policy may inform practice, but in reality, policy in practice is substantiated through contingencies adopted by clinical staff'.

The policy analysis template (Combat Poverty, 2006) echoes this point with the emphasis on what is 'workable' is most likely to be useful and adopted in practice.

\section{What do these principles add?}

These discharge principles synthesise the most relevant aspects from 28 discharge policies to add a specific focus upon the fundamentals of best patient discharge practice for staff working in an AMU or highly acute patient environment. They incorporate an important link to the acute hospital-wide discharge process, to promote patient flow/capacity. This aspect is critical to the functioning of and credibility of an AMU. If these were adopted by AMUs nationally, they would reduce the variation in discharge practice, which could be further integrated within hospital quality standards and thus also improve safety for patient discharge.

\section{What are the consequences for clinical practice?}

The application of the bespoke principles should empower AMU staff to focus upon the relevant and high priority actions, which underpin safe yet expedited patient discharges. These principles offer a standard for the quality of patient discharge that should be provided within an AMU to achieve 'seamless practice' (page 7, point 7, Public Accounts Committee, 2016). It is anticipated that a better quality of discharge will be achieved through less issues raised by patients and carers e.g., 'briefly review the discharge plan involving patients and carers' (point 3). Likewise, the communication and sharing of 
information e.g., 'clarification of services to be reinstated' (point, 6) should improve 'integrated and closer working' from AMUs to primary care to reduce the number of failed discharges, at the point of discharge, from AMUs (NG: 27, 2015, Public Accounts Committee, 2016).

\section{CONCLUSION}

Current UK discharge policy provides little specific accessible guidance for clinical staff expediting patient discharge from AMUs. Complexity across the UK discharge policies is created by its breadth and overlaps. This creates bewilderment regarding how it all fits together to form a coherent process and leads up to the point of patient discharge. If current policy is left unchanged, it requires deciphering by clinical staff, in order to be of any practical use in an AMU. Henceforward, the Scoping review has enabled the breadth of relevant policy to be examined to reveal the fundamental aspects of the discharge process, most relevant to AMUs. Given the very large volumes of patients who are assessed, admitted and subsequently discharged from AMUs on a daily basis, revisiting the discharge policy/principles used in AMUs would seem to be a reasonable first step to improving the patient experience of discharge. 
Ackroyd S, Fleetwood S, eds (2004) Critical Realist Applications in Organization and Management Studies. Routledge, London

Age UK (2014) Factsheet 37: Hospital Discharge Arrangements. http://tinyurl.com/j4pzfy9 (accessed 27 October 2016)

Age UK, Association of Directors of Adult Social Services, British Geriatrics Society et al (2012) Quality Care for Older People with Urgent and Emergency Care Needs. http://tinyurl.com/cebaqz3 (accessed 28 October 2016)

Alberti G for Department of Health (2004) Transforming Emergency Care in

England. http://tinyurl.com/nz9yao5 (accessed 27 October 2016)

Alzheimer's Society (2015) Factsheet 453LP: Hospital Discharge. http://

tinyurl.com/j773sde (accessed 29 October 2016)

Anderson S, Allen P, Peckham S, Goodwin N (2008) Asking the right questions: scoping studies in the commissioning of research on the organisation and delivery of health services. Health Res Policy Syst 6: 7. doi:10.1186/1478-4505-6-7

Arksey H, O'Malley L (2005) Scoping studies: towards a methodological framework. International Journal of Social Research Methodology 8(1): 1932.

Association of Directors of Adult Social Services (2010) Carers as Partners in Hospital Discharge. Improving Carer Recognition, Support and Outcomes within Timely and Supported Discharge Processes. A Review. http://tinyurl. com/39yqmxg (accessed 31 October 2016)

Association of Directors of Adult Social Services, Association of Directors of Children's Services, Care Quality Commission et al (2013) Integrated Care and Support: Our Shared Commitments. http://tinyurl.com/omxvjwm (accessed 27 October 2016)

Atwal A (2002) Nurses' perceptions of discharge planning in acute health care: a case study in one British teaching hospital. J Advanced Nurs 39(5): 450-8. doi: 10.1046/j.1365-2648.2002.02310.x

Atwal A, Mclntyre A, Wiggett C (2012) Risks with older adults in acute care settings: UK occupational therapists' and physiotherapists' perceptions of risks associated with discharge and professional practice. Scand J Caring Sci 26(2): 381-93. doi: 10.1111/j.1471-6712.2011.00946.x

British Medical Association Patient Liaison Group (2014) Hospital Discharge: the Patient, Carer and Doctor Perspective. British Medical Association, London.

Bowers H, Bailey G, Sanderson H, Easterbrook L, Macadam A (2007) Person Centred Thinking with Older People Practicalities and Possibilities. http://

tinyurl.com/hzwv7qo (accessed 1 November 2016

Combat Poverty Agency (2006) How to ... Do Policy Analysis. http://tinyurl. 
com/hejyrlo (accessed 28 October 2016)

Daudt HM, van Mossel C, Scott SJ (2013) Enhancing the scoping study methodology: a large, inter-professional team's experience with Arksey and O'Malley's framework. BMC Medical Research Methodology 13: 48. doi:

10.1186/1471-2288-13-48

Davis MN, Smith ST, Tyler S (2005) Improving transition and communication between acute care and long-term care: a system for better continuity of care. Annals of Long-Term Care 13(5): 25-32

Department of Health (2000) The NHS Plan: A Plan for Investment, a Plan for Reform. http://tinyurl.com/cwuknoz (accessed 27 October 2016)

Department of Health (2002) A manual of discharge practice for health and social care commissioners, managers and practitioners. DH, London

Department of Health (2003a) Discharge from Hospital: Pathway, Process and Practice. http://tinyurl.com/h6k948r (accessed 27 October 2016)

Department of Health (2003b) Discharge from Hospital: getting it right for people with dementia. $\mathrm{DH}$, London

Department of Health (2004) Achieving Timely 'Simple' Discharge from Hospital-A Toolkit for the Multi-Disciplinary Team. http://tinyurl.com/ jevm805 (accessed 27 October 2016)

Department of Health (2007) Urgent Care Pathways for Older People with Complex needs: Best Practice Guidance. http://tinyurl.com/je7qq8n (accessed 27 October 2017)

Department of Health (2010) Ready to Go? Planning the Discharge and the Transfer of Patients from Hospital and Intermediate Care. http://tinyurl.com/ ju8plyj (accessed 27 October 2016)

Department of Health (2011) Safeguarding Adults: The role of Health Service Practitioners. http://tinyurl.com//3ewxwz (accessed 27 October 2016)

Dyer $\mathrm{P}$, Temple M (2007) Doctors, discharge and the interface with the multidisciplinary team. In: Lees L (in Lees, 2007) Nurse-Facilitated Hospital Discharge. MK Publishing, Keswick

Edmans J, Conroy S, Harwood R et al (2011) Acute medical unit comprehensive geriatric assessment intervention study (AMIGOS). Trials

12: 200. doi: 10.1186/1745-6215-12-200

Edmans J, Bradshaw L, Gladman JRF et al (2013) The Identification of Seniors at Risk (ISAR) score to predict clinical outcomes and health service costs in older people discharged from UK acute medical units. Age and Ageing 42(6): 747-53. doi: 10.1093/ageing/aft054

Evidence for Policy and Practice Information Centre (2010) EPPI-Centre 
Methods for Conducting Systematic Reviews. Evidence for Policy and Practice Information Centre, London.

Groene RO, Orrego C, Suñol R, Barach P, Groene O (2012) 'It's like two worlds apart': an analysis of vulnerable patient handover practices at discharge from hospital. BMJ Qual Saf 21 Suppl 1: i67-75. doi: 10.1136/bmjqs-2012-001174

Heath H, Sturdy D, Cheesley A (2010) Discharge Planning. A Summary of the Department of Health's Guidance Ready to Go? Planning the discharge and the transfer of patients from hospital and intermediate care. http://tinyurl.com/ncd2y2g (accessed 31 October 2016)

Health Service Executive (2014) Integrated Care Guidance: A Practical Guide to Discharge and Transfer from Hospital. http://tinyurl.com/jhtxda3 (accessed 27 October 2016)

Henley J, Bennett C, Williamson J, Scott I for Internal Medicine Society of Australia and New Zealand Medical Assessment and Planning Unit Working Group (2006) Position Statement of the IMSANZ. Standards for Medical Assessment and Planning Units in Public and Private Hospitals. http://

tinyurl.com/hxfwb79 (accessed 27 October 2016)

House of Commons Committee of Public Accounts (2016) Discharging Older

People from Acute Hospitals: Twelfth Report of Session 2016-2017. http://tinyurl.com/jrj5lxw (accessed 27 October 2016)

Housing LIN (2012) Essential information for: Hospital-Based Staff. http://

tinyurl.com/guy8eou (accessed 31 October 2016)

Hoyle L, Grant A (2015) Treatment targets in emergency departments: nurses' views of how they affect clinical practice. J Clin Nurs 24(15-16): 2211-8. doi: 10.1111/jocn.12835

Jenkins PF, Barton LL, McNeill GBS (2010) Contrasts in acute medicine: a comparison of the British and Australian systems for managing emergency medical patients. Med J Aust 193(4): 227-8.

Kishore D (2016) NHS in crisis: only four hospitals in England met the A\&E targets in first three months of 2016. International Business Times. May 13. http://tinyurl.com/zr9jfgj (accessed 27 October 2016)

Lees $L$ (2010) Exploring the principles of best practice discharge to ensure patient involvement. Nurs Times 106(25): 10-4

Lees L for The Society for Acute Medicine (2013) Patient Transfer: Principles for the Safe Transfer and Handover of Patients from Acute Medical Units. http://tinyurl.com/zhtasj2 (accessed 28 October 2016).

Lees $L$ (2012) What is best practice for discharge? In: Lees $L$, ed, Timely Discharge from Hospital, M\&K Publishing, Keswick Levac D, Colquhoun $\mathrm{H}$, O'Brien KK (2010) Scoping studies: advancing the methodology. Implement Sci 5: 69. doi: 10.1186/1748-5908-5-69 
Moher D, Liberati A, Tetzlaff J, Altman DG, PRISMA Group (2009) Preferred reporting items for systematic reviews and meta-analyses: the PRISMA statement. Ann Intern Med 151(4): 264-9, W64 National Audit Office (2016) Discharging Older Patients from Hospital. http://tinyurl.com/hnyuy2p (accessed 28 October 2016)

National Audit of Intermediate Care (2014) Assessing Progress in Services for Older People Aimed at Maximising Independence and Reducing Use of Hospitals. http://tinyurl.com/puupt59 (accessed 28 October 2016)

Wales (2013) Passing the Baton: A Practical Guide for Effective Discharge Planning. http://tinyurl.com/37t4rmo (accessed28 October 2016)

National Institute for Health and Care Excellence (2015) Transition between inpatient hospital settings and community or care home settings for adults with social care needs [NG27].http://tinyurl.com/z6qqp7n (accessed 28 October 2016)

NHS Institute for Innovation and Improvement (2008) Discharge Planning. http://tinyurl.com/zlp4kpa (accessed 31 October 2016)

NHS Interim Management and Support (2011) Effective Approaches in Urgent and Emergency Care. Paper 1. Priorities within Acute Hospitals. http://tinyurl. com/qxzfvat (accessed 1 November 2016)

NHS Interim Management and Support (2012) Effective Approaches in Urgent and Emergency Care. Paper 3. Whole Systems Priorities for the Discharge of Frail Older People from Hospital Care. http://tinyurl.com/zygbrms (accessed 27 October 2017).

NHS England (2014) Safe, Compassionate Care for Frail Older People Using an Integrated Care Pathway: Practical Guidance for Commissioners, Providers and Nursing, Medical and Allied Health Professional Leaders. http://tinyurl.com/hkzedjw (accessed 1 November 2016)

NHS England (2015) Quick Guide: Improving Hospital Discharge into the Care Sector. http://tinyurl.com/jy5gw4e (accessed 28 October 2016)

National Library of Medicine (2015) Medical Subject Heading Index. http:// tinyurl.com/zhszq3d (accessed 28 October 2016)

Parliamentary and Health Service Ombudsman (2016) A Report of Investigations into Unsafe Discharges from Hospital. http://tinyurl.com/h2cb8kt (accessed 28 October 2016)

Royal College of Physicians (2007) Acute Medical Care: The Right Person in the Right Setting-First Time. Report of the Acute Medicine Task Force. http://tinyurl.com/grm22au (accepted 28 October 2016)

Royal College of Physicians (2011) Acute Care Toolkit 2: High-Quality Acute Care. RCP, London

Royal College of Physicians (2012) Acute Care Toolkit 3: Medical Care for Frail Older People. RCP, London

Royal College of Physicians (2014) Acute Care Toolkit 10: Ambulatory Emergency Care. RCP, London 
Society for Acute Medicine,West Midlands Quality Review Service (2012) Quality Standards for Acute Medicine Units. http://tinyurl.com/h8ajgg5 (accessed 28 October 2016)

Scottish Government (2009) Best Practice Template: Admissions, Transfer and

Discharge Protocol for Hospital Patients in Scotland. Scottish Government, Edinburgh

Scottish Intercollegiate Guidelines Network (2012) The SIGN Discharge Document. http://tinyurl.com/h2a8fhm (accessed 28 October 2016)

St Mungo's (2012) Improving Hospital Admission and Discharge for People who

are Homeless: Analysis of the Current Picture and Recommendations for Change.

http://tinyurl.com/hyyn368 (accessed 28 October 2016)

Wildridge V, Bell L (2002) How CLIP became ECLIPSE: a mnemonic to assist in searching for 